\title{
Relationship between smoking, weight and attitudes to weight in adolescent schoolgirls
}

\author{
C. Halek, S. Kerry, H. Humphrey, A.H. Crisp and J.M. Hughes \\ Department of Mental Health Sciences, St George's Hospital Medical School, Cranmer Terrace, London \\ SWI7 ORE, UK
}

\begin{abstract}
Summary: A total of 1,932 schoolgirls aged 11-18 from seven schools in the South London area were surveyed using questionnaires which addressed eating patterns, body weight history, attitudes to body weight and shape, menstrual history and current smoking behaviour. They were also weighed and their height was measured. Twelve per cent of the girls were regular smokers and $10 \%$ smoked seven or more cigarettes over a 4 day period. Amongst girls aged 14 and over, $15 \%$ smoked regularly and a further $9 \%$ occasionally. A significant relationship was found between smoking and weight. Smokers were more likely to be moderately overweight in relation to their peers and to have been worried about their weight at some stage. There were differences between girls in state schools and those in independent schools with regard to smoking behaviour and weight. The findings have implications for anti-smoking strategies and health education generally.
\end{abstract}

\section{Introduction}

The level of smoking amongst teenage girls remains a matter of concern, despite major efforts to discourage them from taking up smoking. ${ }^{1,2}$ Recent figures show that about $22 \%$ of 15 and 16 year old girls smoke regularly as against $17 \%$ of boys of the same age, ${ }^{3}$ whereas in adults (aged over 16) the men smoke more (33\% as against $30 \%)$. It is clear that campaigns targeted at smoking prevention in young people have been less successful with girls; ${ }^{2}$ indeed Murray et al. ${ }^{4}$ suggest that health education campaigns may even increase the risks of smoking in girls, by raising their anxiety about their health. Nevertheless, at the end of 1989, a further campaign was launched by the Health Education Authority, specifically aimed at discouraging 11-13 year olds from taking up smoking ${ }^{5}$ and in 1991 the Department of Health formally proposed a target for the year 2000 whereby the present estimated $28 \%$ of women aged $16-19$, who currently smoke, is reduced to $20 \%{ }^{6}$

Weight concern and dieting are also well-known features of female adolescent behaviour. ${ }^{7,8}$ In the UK in 1972 , over $60 \%$ of 17 year olds were concerned about being overweight and the majority had tried to diet. Such figures are fairly constant in developed countries. In the UK as recently as $1988^{8}$ the figure was over $60 \%$ for 14 and 15 year olds. The figure is very much less for boys. Several authors report that young females may resort to extreme, even dangerous methods of weight con-

Correspondence: Professor A.H. Crisp, D.Sc., M.D.

Accepted: 26 October 1992 trol $^{9,10}$ and that such behaviour is linked to beliefs about their weight and body shape, rather than their actual weight. ${ }^{11}$

The idea that female smoking behaviour mig be influenced by attitudes to eating and weight has only recently been examined seriously in the literature, although the idea itself has been around for several decades. ${ }^{12}$ It has sometimes been reported $\frac{0}{\varnothing}$ that smokers are thinner than non-smokers, ${ }^{13}$ and $\cong$ that fear of weight increase, especially in females, $\overrightarrow{\overrightarrow{0}}$ affects motivation to give up smoking. ${ }^{14}$ In both a rural and an urban population studied some 20 years ago $\mathrm{Crisp}^{15}$ found that, amongst middle-aged females, those who smoked were thinner as well as more anxious than other women. Klesges and Klesges ${ }^{16}$ found that overweight females were particularly likely to take up smoking as a method of weight control. Beliefs in the power of smoking as a weight control tool are strongest amongst women. ${ }^{12,17}$

Amongst teenage girls, these issues have received $\frac{D}{\square}$ less attention, despite the high concern about weight and preoccupation with dieting in this age $N$ group and the fact that most adults began smoking $N$ in their teenage years. Charlton ${ }^{9}$ found that most $\mathrm{N}^{2}$ teenage girls held beliefs about smoking and weight $\omega$ similar to those of adult women. She found that smokers were more likely to believe that smoking $\stackrel{O}{C}$ helped keep weight down. She concluded that the $\mathbb{\Phi}^{\circ}$ desire for weight control might be an influential factor in the high incidence of smoking in teenage girls, and that this should be addressed in antismoking material. 
In another study, Feldman et al. ${ }^{18}$ examined the relationship between smoking and weight concern in more detail in their survey of female adolescents in Ottawa. They found a relationship between concern about obesity and smoking which increased with age, with smokers more likely to be concerned. This reached significance at age 18 , but the numbers at this age were small. (Precise age in the teens is also known to affect concern about weight ${ }^{7}$ and smoking prevalence ${ }^{4}$ independently.) Actual weight is not taken into account, although the girls are described as overweight and afraid of obesity. The authors conclude that, although there is a clear relationship between weight concern and smoking, it is not necessarily a causal one. Overweight girls may feel less secure and thus be more susceptible to peer pressure or they may be more orally driven - eating and smoking in response to stresses or because they are less 'restrained' than non-smokers in this respect. The recent study by Townsend et al. ${ }^{19}$ also suggests that adolescent smokers tend to be overweight, although the sample is too small to allow for generalization of this finding.

The study reported here is the first part of an investigation exploring aspects of the hypothesis that cigarette smoking in teenage girls arises partly as a weight control strategy. Thus, smoking provides a non-calorific but still orally gratifying alternative to eating, especially amongst those girls who worry greatly about being too fat and the latter group may also be those whose oral needs and consequent potential for obesity are greatest. ${ }^{20}$ In other words, those girls who smoke are likely to worry more about their weight than other girls. The present report focuses on relationships between smoking, actual weight and fatness and attitudes to weight.

\section{Method}

A total of 1,936 schoolgirls aged 11-18 was surveyed from seven schools in the South London area: three comprehensives (one mixed); two independent single-sex schools (one a boarding school); and two mixed middle schools. Permission was sought via the head teacher of each school and the parents notified. Less than $1 \%$ of parents objected to their daughters taking part in the survey. All the girls present in the school on the survey day participated. The survey was anonymous and consisted of completing questionnaires on weight, attitudes to weight, eating patterns and menstruation, together with smoking behaviour and reasons for smoking. The girls were all weighed by the researchers after completing the questionnaires and their height was measured, so that body mass index (BMI; wt $/ \mathrm{ht}^{2}$ ) could be calculated. The questionnaire relating to weight, eating habits and menstruation is an updated version of that used in a similar population of teenage girls in $1972 .{ }^{7}$ It asks in some detail about weight, weight history, attitudes to weight and shape, eating habits and dietary preferences, as well as eliciting information on menstrual history where applicable.

Prevalence rates for smoking amongst schoolchildren can be difficult to assess, since young people may perceive smoking as a forbidden activity and therefore be reluctant to reveal it as present or past behaviour or may tend to play down the amount that they smoke. Under-reporting is therefore likely. Major studies of smoking amongst school populations carried out by the Office of Population Censuses and Surveys (OPCS) have tackled this by using direct questioning about smoking behaviour followed up by a retrospective diary which asks subjects to record all cigarettes smoked during the preceding seven days. ${ }^{3}$ This consistently has given a higher yield of smokers and smoking behaviour. We followed a similar procedure, but using a 4 day diary (including the weekend), and found the same pattern of increased reporting in the diary when compared with responses to direct questioning.

\section{Statistical method}

The data lend themselves to presentation in contingency tables and the relationships between smoking and weight were explored using the chisquared test.

\section{Results \\ Smoking}

Overall, the prevalence rates for smoking in our population were as follows: those who had never smoked, $44 \%$; those who had smoked only one or two cigarettes, $26 \%$; ex-smokers, $10 \%$; occasional smokers, $8 \%$; and regular smokers, $12 \%$. (Regular smokers are defined by OPCS as smoking at least one cigarette a week.) Ten per cent of the girls admitted smoking seven or more cigarettes in the 4 day period covered by the diary. We defined these as heavier smokers.

\section{Age}

The girls were divided up into age groups on the basis of year bands for their actual age. This gave $108<12$ years, 17912 year olds, 30713 year olds, 47914 year olds, 46015 year old, 22316 year olds, 14117 year olds and $35 \geqslant 18$ years. As would be expected, smoking is associated with age. There is a sharp decrease in the percentage of those who had 
never smoked, from $81 \%$ at age 11 to $35 \%$ at age 15. Thereafter the percentage remains fairly constant. Heavier smoking ( $>6$ cigarettes a week) is a feature from age 13 onwards, being very stable from age 15 .

\section{Weight}

Weight and height in this population obviously increase with age, and level off after age 14. The distribution of wt $/ \mathrm{ht}^{2}$ is skewed, because some girls are very overweight with values over 30 (mean values for over 14s, 21.2-21.5), whereas there are very few girls whose $\mathrm{wt} / \mathrm{ht}^{2}$ is less than 15 . Because of the difficulty in establishing 'normal' BMI in an adolescent population, the girls were divided up into five groups using percentiles for each age group, with 17 and $>18$ year olds taken together. The groups were: very underweight (below 10th percentile); underweight (10th-25th percentile); normal weight (25th-75th percentile); overweight (75th-90th percentile); and very overweight (above 90th percentile). For 14 year olds the BMI ranges were: very underweight, 13.9-17.5; underweight, 17.5-18.8; normal weight, 18.9-22.9; overweight, 22.9-25.6; very overweight $25.7-36.9$.

Using age of menarche as an indicator of growth rate, we found the expected relationships between growth rate and BMI with greater weight being associated with earlier menarche ( $P$ chi-squared: $P<0.0001$ ) (Table I).

\section{Attitude to weight}

The girls were asked if they had been worrying about their weight in the previous 3 months, and if so, why they had been worrying. They were also asked what weight they would prefer to be. The most common reason for worrying was feeling too fat, and the percentage of girls worried for this reason increased with age from $19 \%$ at age 11 to a peak of $49 \%$ at age 17 . The sharpest increase is between 11 and $14(41 \%)$. Other reasons for $\frac{\pi}{2}$ worrying, such as being too thin or out of propor- $\frac{\varrho}{c}$ tion, accounted for approximately $10 \%$ of girls in all age groups. Worry because of feeling too fat matches actual weight, with $5 \%$ of very under- $\overline{0}$ weight girls worried because of feeling too fat $\frac{C}{\partial}$ compared with $87 \%$ of very overweight girls. $\frac{\overline{\bar{p}}}{\overline{2}}$ However, $42 \%$ of normal weight girls worried $\mathbb{8}$ because they felt too fat. Preferred weights for the sample followed the pattern of mean weight, but ${ }^{\circ}$ about $5 \mathrm{~kg}$ below. There was no difference between $\vec{\circ}$ the preferred weight of those girls who wished to be $\overrightarrow{\vec{\omega}}$ thinner and that for the whole sample, although those girls wishing to be thinner were significantly $\bar{C}$ heavier than the others. Thus, the more a girl is 3 . overweight, the further she is from her preferred ; weight. Underweight girls still preferred on the whole to weigh less than their actual weight.

\section{Smoking and weight}

As smoking and weight are both related to age, 을 with values from age 14 remaining fairly constant, $\vec{T}$ analysis was restricted to those aged 14 and over. $\frac{\mathbb{O}}{O}$ There was a significant relationship between smoking and weight with overweight girls more likely to be regular smokers (Table II). Girls who were in the $\vec{\theta}$

Table I Relationship between body mass index (BM) and menarchal age within the total population*

\begin{tabular}{|c|c|c|c|}
\hline BMI group & Mean (years) & $\begin{array}{l}\text { hal age } \\
\text { Standard } \\
\text { deviation }\end{array}$ & $n$ \\
\hline Very underweight & 13.41 & 1.16 & 100 \\
\hline Normal weight & 13.00 & 1.09 & 593 \\
\hline Underweight & 13.38 & 1.04 & 167 \\
\hline Overweight & 12.75 & 0.98 & 188 \\
\hline Very overweight & 12.57 & 1.21 & 111 \\
\hline
\end{tabular}

*Excluding premenarchal girls.

Table II Smoking status by weight group - all girls 14 and over

\begin{tabular}{lcccccc}
\hline & $\begin{array}{c}\text { Very } \\
\text { underweight }\end{array}$ & Underweight & Normal weight & Overweight & $\begin{array}{c}\text { Very } \\
\text { overweight }\end{array}$ & Total \\
\hline Never smoked & 55 & 93 & 263 & 71 & 58 & 540 \\
Tried once & $(10.2 \%)$ & $(17.2 \%)$ & $(48.7 \%)$ & $(13.2 \%)$ & $(10.7 \%)$ & $(40.9 \%)$ \\
& 38 & 42 & 152 & 38 & 30 & 300 \\
Ex-smoker & $(12.7 \%)$ & $(14.0 \%)$ & $(50.7 \%)$ & $(12.7 \%)$ & $(10.0 \%)$ & $(22.7 \%)$ \\
& 13 & 18 & 86 & 26 & 21 & 164 \\
Occasional & $(7.9 \%)$ & $(11.0 \%)$ & $(52.4 \%)$ & $(15.9 \%)$ & $(12.8 \%)$ & $(12.4 \%)$ \\
smoker & 7 & 17 & 63 & 19 & 12 & 118 \\
Regular & $(5.9 \%)$ & $(14.4 \%)$ & $(53.4 \%)$ & $(16.1 \%)$ & $(10.7 \%)$ & $(8.9 \%)$ \\
smoker & 16 & 22 & 98 & 47 & 15 & 198 \\
Total & $(8.1 \%)$ & $(11.1 \%)$ & $(49.5 \%)$ & $(23.7 \%)$ & $(7.6 \%)$ & $(15.0 \%)$ \\
& 129 & 192 & 662 & 201 & 136 & 1,320 \\
& $(9.8 \%)$ & $(14.6 \%)$ & $(50.2 \%)$ & $(15.2 \%)$ & $(10.3 \%)$ & $(100 \%)$ \\
\hline
\end{tabular}

Missing $n=18 . \chi^{2} ; P=0.042$. 
underweight groups were less likely to have tried smoking. Those girls in the very overweight group did not show the same pattern of smoking as those in the overweight group. Overall, girls who had smoked, or were currently smoking heavily, had had an earlier menarche than other smokers (chisquared; $P<0.05$ ).

\section{Smoking and attitude to weight}

There were no significant differences (chi-squared test) in smoking behaviour between those who had worried about their weight in the last 3 months and those who had not within each weight band. However, there was a tendency for those who worried about their weight to smoke more than those who did not worry. When asked if they had ever worried about their weight, smokers overall were significantly more likely to have worried (Table III). There were no differences between the preferred weight of smokers and non-smokers when actual weight was taken into account.

\section{Influence of school type}

Although the effect of social class was impossible to assess accurately, owing to the very loose grasp many children have of their parents' occupations, our sample could be divided according to whether

Table IIIa Answer to question 'Have you been worrying about your weight in the last 3 months?' (all girls 14 and over)

\begin{tabular}{lccc}
\hline & Yes & No & Total \\
\hline Current non-smoker* & 501 & 489 & 990 \\
Current smoker $\dagger$ & $(50.6 \%)$ & $(49.4 \%)$ & $(75.9 \%)$ \\
& 176 & 139 & 315 \\
Total & $(55.9 \%)$ & $(44.1 \%)$ & $(24.1 \%)$ \\
& 677 & 628 & 1,305 \\
& $(51.9 \%)$ & $(48.1 \%)$ & $(100 \%)$ \\
\hline
\end{tabular}

Missing $n=33 . \chi^{2} ; P=0.103$.

Table IIIb Answer to question 'Have you ever worried about your weight?' (all girls 14 and over)

\begin{tabular}{lccc}
\hline & Yes & No & Total \\
\hline Current non-smoker* & 592 & 387 & 979 \\
& $(60.5 \%)$ & $(39.5 \%)$ & $(76.1 \%)$ \\
Current smoker $\dagger$ & 216 & 91 & 307 \\
& $(70.4 \%)$ & $(29.6 \%)$ & $(23.9 \%)$ \\
Total & 808 & 478 & 1,286 \\
& $(62.8 \%)$ & $(37.2 \%)$ & $(100 \%)$ \\
\hline
\end{tabular}

Missing $n=52$. $\chi^{2} ; P=0.002$. ${ }^{*}$ Never smoked, tried once and ex-smoker groups; toccasional and regular smokers. the girls attended state schools or fee-paying independent schools. This facilitates a general comparison between girls from classes 1 and 2 and those from a wider social class range. ${ }^{20}$

\section{Weight and attitudes to weight}

We found differences between the school types in these respects. Thirteen per cent of the state school girls fall into the very overweight group compared with only $6 \%$ of the independent schoolgirls. In particular, state schoolgirls were fatter (BMI) at ages 12-14 than those in independent schools and proportionately more were menstruating before the age of 15 .

As might be expected, girls under 15 in state schools are more likely to worry about being too fat than girls of the same age in independent schools. At 15, the independent schoolgirls worry more, and at 16 there is no difference, with the independent schoolgirls again worrying less after 16 .

Looking at preferred weight by school type, a clear pattern emerges of greatest discrepancy around the time of maximum growth. Thus at ages 14 in state schoolgirls and at 15 and 16 in independent schoolgirls, there is the greatest difference between actual weight and preferred weight. Girls under 14 in independent schools are closer to their preferred weight than other girls (both state and independent).

\section{Smoking}

The pattern of growth is also reflected in smoking behaviour, where the school types are again different, with a higher proportion of state schoolgirls smoking in the younger age groups. This is reversed after the age of 15 , when the independent girls are more likely to be smokers. However, as the proportion of girls in the sixth forms of the state schools was considerably less than in the independent schools, it might be supposed that those remaining in the state schools after the age of 16 were an especially self-selected group. The state school group had a higher proportion of ex-smokers, whereas the independent girls, who started smoking at a later age were less likely to give up smoking once they had started.

\section{Smoking and weight}

Girls were then divided up by BMI percentiles for smoking status. In girls aged over 14 , there are marked differences between state and independent schools (Table IV). The significant relationships between smoking and weight are found only in the independent schoolgirls, with the overweight group more likely to smoke and the underweight group less likely (overall $\chi^{2}: P<0.003$ ). Forty-six per cent 
(a) State schools

Table IV Smoking status and weight group by school type (girls 14 and over)

\begin{tabular}{lcccccc}
\hline & $\begin{array}{c}\text { Very } \\
\text { underweight }\end{array}$ & Underweight & Normal weight & Overweight & $\begin{array}{c}\text { Very } \\
\text { overweight }\end{array}$ & Total \\
\hline Never smoked & 35 & 47 & 145 & 42 & 43 & 312 \\
& $(11.2 \%)$ & $(15.6 \%)$ & $(46.5 \%)$ & $(13.5 \%)$ & $(13.8 \%)$ & $(37.8 \%)$ \\
Tried once & 30 & 33 & 116 & 32 & 29 & 240 \\
& $(12.5 \%)$ & $(13.8 \%)$ & $(48.3 \%)$ & $(13.3 \%)$ & $(12.1 \%)$ & $(29.1 \%)$ \\
Ex-smoker & 9 & 13 & 60 & 20 & 16 & 118 \\
& $(7.6 \%)$ & $(11.0 \%)$ & $(50.9 \%)$ & $(17.0 \%)$ & $(13.6 \%)$ & $(14.3 \%)$ \\
Occasional & 2 & 9 & 19 & 10 & 9 & 49 \\
smoker & $(4.1 \%)$ & $(18.4 \%)$ & $(38.8 \%)$ & $(20.4 \%)$ & $(18.4 \%)$ & $(5.9 \%)$ \\
Regular & 12 & 13 & 49 & 21 & 11 & 106 \\
smoker & $(11.3 \%)$ & $(12.3 \%)$ & $(46.2 \%)$ & $(19.8 \%)$ & $(10.4 \%)$ & $(12.9 \%)$ \\
Total & 88 & 115 & 389 & 125 & 108 & 825 \\
& $(10.7 \%)$ & $(13.9 \%)$ & $(47.2 \%)$ & $(15.2 \%)$ & $(13.1 \%)$ & $(100 \%)$ \\
\hline
\end{tabular}

Missing $n=27 . \chi^{2} ; P=0.691$.

(b) Independent schools

\begin{tabular}{lcccccc}
\hline & $\begin{array}{c}\text { Very } \\
\text { underweight }\end{array}$ & Underweight & Normal weight & Overweight & $\begin{array}{c}\text { Very } \\
\text { overweight }\end{array}$ & Total \\
\hline Never smoked & 10 & 34 & 76 & 24 & 9 & 153 \\
& $(6.5 \%)$ & $(22.2 \%)$ & $(49.7 \%)$ & $(15.6 \%)$ & $(5.9 \%)$ & $(32.0 \%)$ \\
Tried once & 18 & 18 & 64 & 11 & 8 & 119 \\
& $(15.1 \%)$ & $(15.1 \%)$ & $(53.8 \%)$ & $(9.2 \%)$ & $(6.7 \%)$ & $(24.9 \%)$ \\
Ex-smoker & 5 & 5 & 27 & 6 & 5 & 48 \\
& $(10.4 \%)$ & $(10.4 \%)$ & $(56.3 \%)$ & $(12.5 \%)$ & $(10.4 \%)$ & $(10.0 \%)$ \\
Occasional & 3 & 8 & 44 & 9 & 2 & 66 \\
smoker & $(4.6 \%)$ & $(12.1 \%)$ & $(66.7 \%)$ & $(13.6 \%)$ & $(3.0 \%)$ & $(13.8 \%)$ \\
Regular & 4 & 9 & 49 & 26 & 4 & 92 \\
smoker & $(4.4 \%)$ & $(7.8 \%)$ & $(53.3 \%)$ & $(28.6 \%)$ & $(4.4 \%)$ & $(19.3 \%)$ \\
Total & 40 & 74 & 260 & 76 & 28 & 478 \\
& $(8.4 \%)$ & $(15.5 \%)$ & $(54.4 \%)$ & $(15.9 \%)$ & $(5.9 \%)$ & $(100 \%)$ \\
\hline
\end{tabular}

Missing $n=8 \cdot \chi^{2} ; P=0.003$.

of the overweight girls in independent schools smoke, as against $27 \%$ of state schoolgirls. Higher levels of smoking are found in the independent schoolgirls overall.

\section{Discussion}

When weight and attitudes to weight are considered, our results are consistent with those of other studies in that they show that teenage girls worry about their weight, that worry about weight is related to actual weight and that worry about being too fat increases with age. ${ }^{21}$ Those girls who worry more about being fat are actually fatter than their peers. Those girls who are overweight in relation to their peer group are more likely to smoke, although this relationship does not pertain for those who are extremely overweight. Those girls who are underweight are less likely to have tried smoking than their peers. Those girls who have worried about their weight in the past are more. likely to smoke, although this relationship does not pertain to current concern about weight.

Weight is, of course, a marker of growth, and our results confirm that smoking behaviour is also' growth related, in that it really takes hold aroundo the time of menarche. Thus, the younger girls in independent schools are less likely to be menstruat-9 ing than their counterparts in state schools and also $\frac{}{2}$ less likely to be smoking. Similarly it is established that those girls with an early menarche are heavier than those with late menarche, ${ }^{22}$ and this was true for our sample. We also found that those girls whos were ex-smokers or smoked more heavily had an $\omega$ earlier menarche than girls in other smoking? groups, a finding consistent with the association between being overweight and smoking. One ex-迹 planation for this might be that girls with an early menarche are likely to try smoking at younger ages, ${ }_{0}^{\circ}$ and that while some of them give up, others becomeet increasingly addicted to cigarette smoking. Crisp ${ }^{23} \stackrel{\square}{\Phi}$ 
has suggested elsewhere that early menarche (and thus early puberty) confronts girls with the problems of adolescence at an earlier age than others, and that sensitivity about weight is one expression of anxiety about the difficulties this brings.

Our finding that overweight girls in independent schools, where being overweight is less 'normal' than in state schools, are particularly at risk of smoking supports this idea that being 'abnormal' exposes the individual to particular anxieties and pressures, especially in a group for whom it is already known that there is increased pressure to be slim. ${ }^{24}$ Peer pressure is also a recognized influence on teenage smoking, especially amongst girls. ${ }^{25}$ Thus, it may be that the suggestion of Feldman $e t$ $a l{ }^{18}$ is in part substantiated by our data: overweight girls may feel less secure within a 'normal' weight peer group and so be more likely to succumb to behaviour which is reinforced by their peers, in order to belong. It will be necessary to examine in more detail the factors associated with smoking amongst overweight girls as well as their co-existing anxieties.

Another important way of considering these data is in terms of the effect of personality on both smoking and eating behaviour. Mangan and Golding $^{26}$ found that younger smokers were more likely to smoke for pathological reasons and older ones for psychological and biological reasons. They also found that oral dependency was a factor which discriminated between smokers and non-smokers. Crisp $^{7}$ has reported that many adolescent girls resort to numerous strategies for self regulation, such as dancing, gymnastics or other bodily methods of control. If this need for self regulation is pathological, it may lead to alcohol or drug dependence, phobias or eating disorders. In this context, smoking could be seen as one other attempt to regulate impulses which could be thought of as out of control. In overweight teenagers, these impulses may have found expression in overeating, particularly in those adolescents for whom frank adolescent chaos might be particularly threatening or unacceptable. This might account in part for the apparent influence of social class, or at least social milieu. Although we did find that girls from state schools were more likely to try smoking, especially at younger ages, those from independent schools smoked more once they had started and appeared less likely to give up. Thus the association of smoking with lower social class found by Coombs et al. ${ }^{27}$ does not appear to be substantiated in our data, although this could be due to the differences in sampling and methodology.

One of the interesting findings of the data is the clear difference in this sample between girls in state and independent schools in their smoking and weight patterns. The relationship between smoking and weight and attitude to weight appears to be stronger in the independent girls and reasons for this have been discussed above. Although it is not possible to generalize this result from a sample of seven schools to the whole population, nevertheless the differences between school type were marked and cannot be dismissed. If they were to hold true for other populations, this could have implications not only for interpreting the findings of research on schoolgirl populations generally, but also importantly for considering how to prevent or decrease smoking in teenage girls. Health education targeted at smoking in independent schools may be accorded lower status or thought to be less necessary than in state schools and this may in part account for the higher rates of smoking found by us for the independent schoolgirls. An observation made during the survey was that teachers in many disciplines in the state schools were keen to incorporate the issues raised by the questionnaires into their teaching material and classwork, whereas the independent school teachers did not show the same interest, at least not to the researchers. One (independent) school had very strong penalties and deterrents for smoking; the staff believed that smoking was minimal but the girls revealed one of the highest smoking rates in the study.

The other implications for health education based on the initial findings of this study might be that preventing smoking needs to be linked to addressing concerns about weight, appearance and attractiveness and anxieties over general acceptability, especially for those girls who are overweight. ${ }^{24}$ Although the majority of girls over 14 are concerned about their weight and worry about being too fat, they are more likely to worry if they are overweight in relation to their peers.

It seems then that a relationship between weight and smoking in teenage girls is confirmed, and that this relationship involves both concern about weight and actual weight. It is however not a straightforward relationship, in that smokers are not currently more concerned about their weight than non-smokers in the same weight group and very overweight girls are not more likely to smoke than other girls. The results do suggest, however, that concern about weight at some stage is a factor more associated with subsequent smoking behaviour. If Klesges ${ }^{\prime 16}$ observation in adults holds true for adolescents, then some overweight girls may well try smoking as an attempt to curb further weight gain, even though it may not result in their becoming substantially thinner. On the other hand, if Crisp's ${ }^{15}$ findings in adult populations hold true for these girls, smoking may eventually have a substantial effect on their weight, in that smoking seems to be associated with thinness in older women. One could postulate that girls who are more likely to be overweight but do not go on to 
smoke for reasons to do with personality or social factors may be those who become very overweight. Perhaps older women who have always been obese and who are demonstrably less anxious than their peers ${ }^{28}$ are those who did not smoke in their teens, and a retrospective study of this could be worthwhile. Meanwhile, health education aimed at learning about alternative, healthy methods of selfregulation, self-presentation and management of feelings and anxieties may well be more productive for teenage girls than specific and circumstantial warnings about the deleterious effects of smoking on their health.

\section{References}

1. Department of Health and Social Security. On the State of the Public Health. HMSO, London, 1986.

2. Department of Health and Social Security. On the State of the Public Health, HMSO, London, 1987.

3. Office of Population Censuses and Surveys. Smoking Amongst Secondary School Children. HMSO, London, 1988.

4. Murray, M., Swan, A.V. \& Clarke, G. The long term effect of a school-based anti-smoking programme. $J$ Epidemiol Commun Health 1984, 38: 247-252.

5. Department of Health. On the State of the Public Health. HMSO, London, 1990.

6. Department of Health. The Health of the Nation. HMSO, London, 1991.

7. Crisp, A.H. Regulation of the self in adolescence with particular reference to anorexia nervosa. Trans Med Soc Lond 1985, 100: 67-74.

8. Balding, J. Young People in 1988. HEA Schools Health Education Unit, Exeter, 1989.

9. Charlton, A. Smoking and weight control in teenagers. Public Health 1984, 98: 277-281.

10. Klesges, R.C., Mizes, J.S. \& Klesges, L.M. Dieting strategies in a college population. Int $J$ Eating Disord 1987, 6: 406-417.

11. Greenfield, D., Quinlan, D., Harding, P., Glass, E. \& Bliss, A. Eating behaviour in an adolescent population. Int $J$ Eating Disord 1987, 6: 99-111.

12. Action on Smoking and Health. Women and Smoking. ASH, London, 1986.

13. Wack, J.T. \& Rodin, J. Smoking and its effects on body weight and the system of caloric regulation. Am J Clin Nutr 1982, 35: 366-380.

14. Grube, J.W., McGree, S. \& Morgan, M. Beliefs related to cigarette smoking amongst Irish college students. Int J Addict 1986, 21: 701-706.

15. Crisp, A.H. Some psychopathological aspects of obesity. In: Lacey, J.H. \& Sturgeon, D.A. (eds) Proceedings of the 15th European Conference on Psychosomatic Research. 1986.

16. Klesges, R.C. \& Klesges, L.M. Cigarette smoking as a dieting strategy in a university population. Int J Eating Disord 1988, 7: 413-419.

\section{Acknowledgements}

Professor Crisp expresses his appreciation to the follow- $\stackrel{D}{Q}$ ing bodies for the funding they have contributed to this $C$ project. The Wandsworth and Merton Mental Health $\vec{F}$ Unit which supports Ms Halek; the Cancer Research $\stackrel{\text { ? }}{?}$ Campaign which supports Mr Hughes; the European? Community Commission - Europe against Cancer Cam-흐 paign which has supported Ms Kerry and Mrs Humphrey $\frac{\bar{\rho}}{\triangle}$ and Marks and Spencer which is supporting Mrs Hum- $\Phi$ phrey.

17. Jacobson, B. Beating the Ladykillers. Pluto Press, London, 1986.

18. Feldman, W., Hodgson, C. \& Corber, S. Relationship between higher prevalence of smoking and weight concern $\vec{O}$ amongst adolescent girls. Can J Public Health 1985, 76: 205-206.

19. Townsend, J., Wilkes, H., Haines, A. \& Jarvis, M. Adolescent smokers seen in general practice: health, lifestyle, physical $\rightarrow$ measurements and response to smoking advice. $\mathrm{Br}$ Med $J \mathbb{D}$ 1991, 303: 947-950.

20. Crisp, A.H. The possible significance of some behavioural $\frac{d}{d}$ correlates of weight and carbohydrate intake. $J$ Psychosom Res 1967, 11: 117-131.

21. Wardle, J. \& Marshland, L. Adolescent concerns abogt weight and eating; a social-developmental perspective. $J \omega$ Psychosom Res 1990, 34: 377-391.

22. Crisp, A.H., Douglas, J.W.B., Ross, J.M. \& Stonehill, 胥. Some developmental aspects of disorders of weight. $J$ Psychosom Res 1970, 14: 313-320.

23. Crisp, A.H. Premorbid factors in adult disorders of weight, with particular reference to anorexia nervosa (weight phobia). $\frac{\circ}{\mathbb{D}}$ A literature review. J Psychosom Res 1970a, 14: 1-22.

24. Garrow, J.S. Obesity and Related Diseases. Churchill Living- $\overrightarrow{\vec{T}}$ stone, Edinburgh, 1988.

25. Presson, C.C., Chassin, L., Sherman, S.J., Olshavsky, R., Besenberg, M. \& Corty, E. Predictors of adolescents' intention to smoke: age, sex, race and regional differences. Int $\boldsymbol{J}$ Addict 1984, 19: 503-519.

26. Mangan, G.L. \& Golding, J.F. The Psychopharmacology of 3 Smoking. Cambridge University Press, Cambridge, 1985.

27. Coombs, R.H., Fanzy, F.I. \& Gerber, B.E. Patterns of cigarette, alcohol and other drug use among children and adolescents. Int J Addict 1986, 21: 897-913.

28. Crisp, A.H. \& McGuiness, B. Jolly fat. The relation between obesity and psychoneurosis in the general population. $\mathrm{Br} \mathrm{Med} O$ $J$ 1976, 1: 7-9. 


\section{Errata}

Re: Postgraduate Medical Journal 1993, 69: Re: Postgraduate Medical Journal 1993, 69: 384-388.

Combined transhepatic and endoscopic proce100-106.

dures in the biliary system: A.G. Verstandig, E. Goldin, T. Sasson, G. Weinberger, D. Wengower, A. Fich and E. Lax

We apologise for printing the incorrect illustration for Figure 3 of this paper. The correct figure with legend is reproduced below.

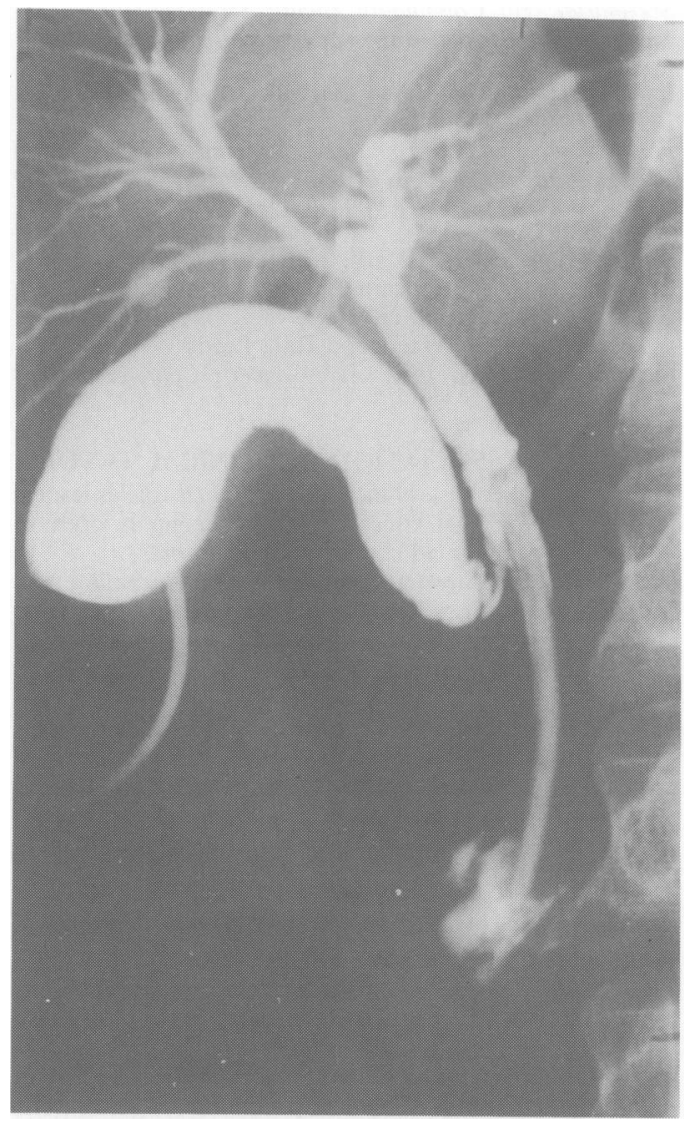

Relationship between smoking, weight and attitudes to weight in adolescent schoolgirls: C. Halek, S. Kerry, H. Humphrey, A.H. Crisp and J.M. Hughes.

An author's error occurred in this paper. The statistical test used to compare menarchal age was an $F$ test not a chi-square test as reported. The $P$-values are correct.

Figure 3 Final antegrade cholangiography (in this case via a cholecystostomy catheter) demonstrating good stent position and free flow of contrast to the duodenum. 